MENTAL

HEALTHLAW

PROFILES

\title{
Mental health law profiles
}

\author{
George Ikkos
}

Consultant Psychiatrist in Liaison Psychiatry, Royal National Orthopaedic Hospital, London, UK, emailikkos@doctors.org.uk
In this instalment of mental health law profiles we travel to two countries which neighbour each other on the west side of Latin America. They have important natural resources and complex histories of indigenous civilisations decimated by colonial conquests, later wars of liberation from the imperial centre and legacies of social inequality and violent internal conflict during the Cold War era. They also differ from each other in important respects, such as levels of ethnic diversity and economic development, Peru being more ethnically diverse and Chile more economically developed. In both countries, the authors inform us, there is cause for concern about the welfare and human rights of people who are mentally ill.

There is an increasing realisation in recent decades of the need for improvement in both Chile and Peru. Both the 1978 American Convention on Human Rights and the Peruvian Constitution (the latter unusually perhaps) make specific reference to mental illness and its management, and provide some welcome foundations to build on. It is good to read that local policies advocate the establishment of community facilities for the care of patients with a mental illness and recognise the importance of least restrictive treatment. However, definitions of mental illness, rights of appeal and engagement of informal carers are unclear or lacking in important respects and offer examples of the magnitude of the task ahead.

The establishment of the National Commission for the Protection of People with Mental Illness (CNPPAEM) in Chile, with responsibility for letting the Court of Appeal know of any violation of the rights of those affected by a mental or intellectual disability, suggests a level of commitment in that society to go beyond policy and towards implementation; this is something that has often been reported as lacking in previous articles on some other countries in this series. The proposed Law 29889 in Peru, as reported here, also offers hope for progress. Those working locally to address shortcomings deserve the active support of the international psychiatric community.

\section{MENTAL} HEALTHLAW PROFILE

\section{Mental health legislation in Chile}

\author{
Andrea Bahamondes ${ }^{1} \mathrm{MD}$, Alvaro Barrera ${ }^{2}$ MRCPsych MSc PhD, \\ Jorge Calderón ${ }^{3}$ MD MRCPsych, Martin Cordero ${ }^{4}$ MD FRCPsych and Héctor Duque ${ }^{5}$ MD
}

'Professor of Psychiatry, Facultad de Ciencias de la Salud, Universidad Mayor; Departamento de Salud Mental, Servicio Médico Legal, Ministerio de Justicia, Chile

${ }^{2}$ Consultant Psychiatrist, Oxford Health NHS Foundation Trust, UK ${ }^{3}$ Associate Professor. Departamento de Psiquiatría, Pontificia Universidad Católica de Chile, Chile, email jcaldep@ gmail.com

4Unidad de reparación de víctimas, Ministerio del Interior Chile

${ }^{5}$ Liaison Psychiatry Unit, Hospital San Borja-Arriarán and Clínica Alemana, Santiago, Chile
Chile does not have a mental health law or act, and no single legal body protecting those deemed to be afflicted by a mental disorder, setting standards of care and protecting and promoting their rights. Instead, pieces of mental health legislation are scattered about in different legal and administrative documents, including the country's Constitution, Health Code, Criminal Code and Civil Code. Remarkably, mental health legislation was the object of virtually no change or amendment from the middle of the 19th century until the year 2001. New pieces of legislation have been issued since but, despite improvements in the protection of people suffering from a mental illness, a mental health law in Chile is still needed.

Chile lacks a specific mental health law that would provide a legal framework for the care of people with mental ill-health. Instead, the country's mental health legislation is scattered across different legal and administrative documents, ranging from the country's Constitution, to the Health Code, the Criminal Code, the Civil Code and other documents. The first legislation regulating the care of those who are mentally ill, issued in 1856, was the 'Mad House Law', which was mostly inspired by a French law of 1838 . In 1927 the General Code for the Organisation and Care Provision of Mental Health Services, Hospitalisation and Confinement of the Insane enacted articles 178 and 261 of the National Health Code, regulating both private and public mental healthcare institutions (Vásquez, 1935; Naveillan, 1991). There were no other changes until the year 2001.

\section{Decree 570}

In January 2001 the government issued the Code for the Hospitalisation of the Mentally Ill and for 
the Appropriate Institutions (Decree 570), which abolished the General Code of 1927. Importantly, since Decree 570 was an administrative presidential act and not a law approved by the national parliament, it operated more like a code of practice.

\section{Definitions}

A psychiatric patient is defined as 'a person suffering from a mental disorder who is under the care and supervision of medical services'. Mental disorder is in turn defined as a 'morbid condition affecting an individual in varying degrees, their mental function, organism, personality and its social interaction, either temporarily or permanently'.

\section{Admission}

Decree 570 aims to establish a fair and clear decision-making process that takes into account patients' rights. In section II, it specifies that hospitalisation can be recommended only by a medical doctor, ideally the treating physician, who should be an accredited psychiatrist. Section III indicates that the hospitalisation of people with mental disorders should be done in such a way as to minimise the impact upon their personal rights and freedom, and should be undertaken only if they cannot be assessed or treated as out-patients, or if their mental state poses an imminent risk of physical, psychological or psychosocial harm to themselves or others.

In article 10, Decree 570 indicates that admission to hospital can be voluntary or compulsory. There are three types of compulsory hospitalisation: emergency, administrative and judicial.

An emergency admission (article 13) can take place for a period of assessment of up to 72 hours. If further time is necessary but the patient does not consent to it, the treating clinician must inform the respective local health authority, which, within 72 hours, must decide if it authorises what would then be an administrative admission (see below). If it rejects the extension, the patient is discharged from hospital; relatives do not have a formal role in this process.

An administrative admission (article 14) is one in which a health authority authorises the compulsory hospitalisation of an individual who appears to be suffering from a mental disorder but who does not agree to be admitted and who is considered to be a risk to self or others, or who disrupts the public order. This is done at the request of the police, relatives, the treating physician or a member of the public. Administrative admissions must be reviewed every 30 days by another psychiatrist, who must inform the health authority that originally authorised the hospitalisation.

Lastly, a judicial admission is a compulsory admission which has been ordered by the courts in the context of criminal or civil proceedings.

\section{Discharge}

Article 41 of Decree 570 indicates that discharge from any compulsory admission will be determined by the health authority that authorised it at the request of the treating physician. Independent legal review by a tribunal is not considered, unless the case is one of judicial admission; again, relatives do not have a role in this process.

\section{Treatment}

Decree 570 also regulates hospital treatment. Reversible treatment can be carried out without consent (article 22) only for children (where consent is provided by parents or a guardian) and for elderly people who lack capacity to consent; relatives' consent and the agreement of the director of the hospital is required in these cases. Reversible treatment can also be carried out for unconscious patients, provided that the treatment is required to preserve their life or prevent further deterioration of health, as well as for patients whose compulsory admission has been ordered by a court (judicial admission).

Article 25 indicates that for non-consensual irreversible treatments (e.g. psychosurgery, sterilisation and long-term hormone therapy) all the relevant information must be sent to the National Commission for the Protection of People with Mental Illness (CNPPAEM) at the Department of Health. Between the years 2000 and 2013 a total of 31 cases were referred to the Commission for the consideration of psychosurgery, of which 8 were approved (for obsessive-compulsive disorder). Regarding sterilisations, 63 applications were made between 2003 and 2013, of which 26 were approved.

Decree 570 does not deal with compulsory community treatment or the treatment of people with drug addictions or intellectual disabilities.

\section{Law 20.584}

Since July 2012, Law 20.584 has regulated the rights and duties of any person in relation to actions linked to their healthcare. In its paragraph 8, it deals with the rights of people affected by what it calls a 'mental or intellectual disability'. Of note, Law 20.584 does not define with precision the concept of mental disorder; indeed, it seems to conflate mental disorder and intellectual disability.

The relationship between Law 20.584 and Decree 570 is complex, as the latter remains valid and there are areas where Law 20.584 does not provide guidance.

In its article 29 Law 20.584 confirms the role of the CNPPAEM and assigns to it responsibility for letting the Court of Appeal know of any violation of the rights of those affected by a mental or intellectual disability (Box 1). The Commission is to be composed of two members of a mental health professional association, one lawyer, two representatives of a mental health academic association, two representatives of a service users' association, two representatives of a relatives' association and one representative of the health authority.

Regarding access to records and confidentiality, in article 23 Law 20.584 establishes that in 
Box 1 Responsibilities of the National Commission for the Protection of People with Mental Illness (CNPPAEM)

- Protect and promote the human rights of people affected by mental or intellectual disability.

- Suggest to the health authority ways of joint working with human rights agencies.

- Monitor invasive and/or irreversible treatments.

- Monitor potential infringement of patients' human rights.

- Monitor deaths during hospital stays.

\section{Box 2 Criteria for compulsory admission}

Compulsory admission is indicated if:

- the mental state of the individual poses an imminent risk of harm to him- or herself or others

- the admission has a therapeutic goal

- a less restrictive option is not available

- the patient's views have been considered whenever possible; otherwise, the opinion of the legal representative must be sought. cases where the medical information is considered harmful for the patient, access to the clinical records can be restricted or denied to the patient but it can be provided to their legal representative.

Article 24 indicates that if a person with a mental disability is unable to give consent to invasive and/or irreversible treatments, an opinion from the local ethics committee should be sought.

Article 25 indicates the conditions required for a compulsory admission (Box 2). In particular, the regional health authority and the CNPPAEM must be informed of all such admissions.

Law 20.584 does not provide specific procedures for the process of discharge from hospital; it mentions only the potential involvement of the Court of Appeal at the request of the CNPPAEM, the patient or legal representative. Law 20.584 provides some guidance regarding indications for physical and pharmacological restraint and confinement; it also mentions the involvement of patients in research.

\section{Areas requiring clarification}

The notion of patient capacity is in need of legal clarification. In fact, a procedure for the assessment of capacity to consent to treatment is yet to be defined, so the opinion of the treating physician is not based on an explicit legal test. Similarly, the definition of legal representative remains rather vague, with the risk that, in practice, that role may be allocated to anyone accompanying the patient, even when this is not necessarily in the patient's best interest.

\section{Conclusion}

From the year 2000 onwards an awareness of the need for more appropriate mental health legislation started to develop. Decree 570, although far from perfect, was a step in the direction of setting standards of care in hospitals and clinics. Also, since Chile's return to democratic rule in 1990 , community mental healthcare has gradually expanded, non-pharmacological interventions have been implemented, and access to medication has improved (World Health Organization, 2007).

Despite these developments, our view is that the care of patients with severe mental illness continues to be marked by stigma, discrimination and, last but not least, abuse due to the lack of a coherent legal framework. In fact, the coexistence of laws and codes whose relationship to each other is unclear may not make the situation better. We believe that modern, rights-centred and evidencebased mental health legislation in Chile is urgently required.

\section{References}

Naveillan, P. (1991) Textos Legales sobre Salud y Enfermedad Mental [Legal Texts on Health and Mental Health]. Alborada.

Vásquez, I. (1935) Asilos de Enajenados: memoria de prueba para optar al grado de licenciado en la facultad de Ciencias Jurídicas y Sociales de la Universidad de Chile [Mental Health Nursing: Memory Test for the Degree of Bachelor of the Faculty of Law and Social Sciences of the University of Chile]. Imprenta de la cárcel de Valparaíso.

World Health Organization (2007) Informe WHO-AIMS sobre sistema de salud mental en Chile [WHO-AIMS Report on Mental Health System in Chile]. WHO. 